Published in final edited form as:

Exp Neurol. 2007 May ; 205(1): 101-107.

\title{
The selective $\mathrm{k}$-opioid receptor agonist U50,488 reduces L-dopa- induced dyskinesias but worsens parkinsonism in MPTP-treated primates
}

\author{
Heather Cox, Daniel M. Togasaki, Li Chen, J. William Langston, Donato A. Di Monte, and \\ Maryka Quik \\ The Parkinson's Institute, 1170 Morse Avenue, Sunnyvale, CA 94089, USA
}

\begin{abstract}
Several lines of evidence demonstrate that the striatal enkephalinergic system may be involved in the development of LIDs. Preproenkephalin-B (PPE-B) transcript levels are elevated with LIDs and there are also declines in $\kappa$ - and other opioid receptors in different regions of the basal ganglia. If reduced $\kappa$-opioid receptors are linked to LIDs, it is possible that drugs that stimulate this subtype may decrease dyskinesias. We therefore initiated experiments to investigate the effect of $\kappa$-opioid receptor activation on LIDs. We first tested the selective $\kappa$-agonist U50,488 in rats with unilateral lesions of the nigrostriatal pathway. Chronic L-dopa treatment induced abnormal involuntary movements, including axial, orolingual and forelimb dyskinesias contralateral to the lesion. U50,488 administration prior to L-dopa treatment reduced these movements by $70 \%$, suggesting that U50,488 has potential as an anti-dyskinetic treatment. We next tested its effect in a parkinsonian nonhuman primate model, which offers the advantage that parkinsonism and LIDs can clearly be differentiated and that the dyskinesias are similar to those in parkinsonian patients. 1-Methyl-4-phenyl-1,2,3,6tetrahydropyridine (MPTP)-lesioned monkeys were treated with L-dopa $(5 \mathrm{mg} / \mathrm{kg}$, p.o.) twice daily for 3 weeks to induce dyskinesias. As in the rodent model, U50,488 $(0.1-1.0 \mathrm{mg} / \mathrm{kg}$, i.m. $)$ decreased LIDs in a dose-dependent fashion. However the anti-parkinsonian effect of L-dopa was similarly reduced, and side effects developed, including sedation and vomiting. These data suggest that $\kappa-$ opioid agonists such as U50,488 may not be clinically useful antidyskinetic agents because they also reverse the anti-parkinsonian effect of L-dopa.
\end{abstract}

\section{Keywords}

dyskinesia; rat; monkey; U50; 488; Parkinson's disease

\section{Introduction}

The pathophysiology of L-dopa-induced dyskinesias (LIDs) is still unclear most likely because multiple neurotransmitter systems are involved in their etiology (Bezard et al.,

2001,Linazasoro, 2005). This includes the opioid system, which is widespread throughout the basal ganglia. Extensive studies have shown that the enkephalinergic system is altered both with nigrostriatal damage and subsequent treatments to alleviate the functional consequences of dopaminergic denervation, such as L-dopa administration. For instance, nigrostriatal

\footnotetext{
*Corresponding author. Tel.: 1-408-542-5601; fax: 1-408-734-8455. E-mail address: mquik@ parkinsonsinstitute.org (M. Quik)

Publisher's Disclaimer: This is a PDF file of an unedited manuscript that has been accepted for publication. As a service to our customers we are providing this early version of the manuscript. The manuscript will undergo copyediting, typesetting, and review of the resulting proof before it is published in its final citable form. Please note that during the production process errors may be discovered which could affect the content, and all legal disclaimers that apply to the journal pertain.
} 
degeneration increases preproenkephalin-A (PPE-A) mRNA levels in the indirect pathway, that is, striatal neurons projecting to the external globus pallidus; this contrasts with effects on PPE-B mRNA levels that are decreased in striatal outputs to the internal globus pallidus, or the direct pathway (Morissette et al., 1997,Cenci et al., 1998,Duty et al., 1998,Henry et al., 1999,Quik et al., 2002,Tel et al., 2002,Henry et al., 2003,Aubert et al., 2006). LIDs, on the other hand, are linked to increases in PPE-B transcript levels, while changes in PPE-A do not correlate well with the development of dyskinesias (Cenci et al., 1998,Duty et al., 1998,Henry et al., 1999, Quik et al., 2002, Tel et al., 2002,Henry et al., 2003,Aubert et al., 2006).

The products of PPE expression, that is, endogenous opioid compounds such as the enkephalin pentapeptides and dynorphin, exert their effects by interacting with opioid receptors of which there are three primary subtypes, $\mu$-, $\delta$ - and $\kappa$-opioid receptors (Gouarderes et al., 1993,Meng et al., 1993,Kaneko et al., 1995,Satoh and Minami, 1995). These receptors are present throughout the basal ganglia and are modulated both by nigrostriatal damage and L-dopa treatments in various basal ganglia regions (Johansson et al., 2001,Aubert et al., 2006), with a decline in $\kappa$ - and/or $\mu$-opioid receptor binding in different basal ganglia regions with LIDs (Johansson et al., 2001,Aubert et al., 2006). The lower receptor levels may indicate that function is not optimal at these opioid receptor subtypes, and that their stimulation may lead to a reduction in LIDs. Indeed, studies in rodents showed that the U50,488 modulates L-dopainduced motor alterations in parkinsonian rats, suggesting that $\kappa$-opioid agonists might be of clinical benefit in Parkinson's disease (Marin et al., 2003).

The objective of this study was to extend these studies and determine the effectiveness of a select $\kappa$-opioid agonist U50,488 on LIDs in parkinsonian primates. This model offers the advantage that L-dopa-induced effects on parkinsonism and dyskinesias are easily recognizable, with behavioral features closely resembling those in Parkinson's disease patients.

\section{Methods}

\section{Rodent Studies}

Nigrostriatal lesioning and drug treatments-Male Sprague-Dawley rats (200 - 250

g) were purchased from Charles River Laboratories, Wilmington, MA, USA. After 1-2 weeks acclimatization, they were anesthetized with pentobarbital $(50 \mathrm{mg} / \mathrm{kg}$, i.p.) and placed in a stereotaxic apparatus (David Kopf Instruments, Tujunga, California, USA). They were then lesioned with 6-hydroxydopamine (Sigma, St. Louis, MO, USA) at two sites within the right ascending dopamine fiber bundle, as described (Cenci et al., 1998), at the following coordinates relative to the Bregma and the dural surface: $(i)$ anteroposterior -4.4 ; lateral, +1.2 ; ventral, -7.8 ; tooth bar at -2.4 and (ii) anteroposterior -4.0 ; lateral, +0.75 ; ventral, -8.0 ; tooth bar at +3.4 (Paxinos and Watson, 1986). A $10 \mu \mathrm{l}$ Hamilton syringe was used to inject $3 \mu \mathrm{l}$ of 6hydroxydopamine $(2 \mu \mathrm{g} / \mu \mathrm{l})$ slowly into each target site. All procedures conformed to the National Institute of Health's Guide for the Care and Use of Laboratory Animals and were approved by the Institutional Animal Care and Use Committee.

Two weeks later, rotational behavior was tested following apomorphine $(0.5 \mathrm{mg} / \mathrm{kg}$, s.c. $)$ in an automated behavioral measurement apparatus (ROTOMAX, AccuScan Instruments Inc.

Columbus, Ohio, USA) (Cenci et al., 1998). Rats with $>100$ contralateral turns within $1 \mathrm{~h}$ were used for further experiments. Six weeks post-lesioning, L-dopa was administered daily (i.p.) for 21 days $(6 \mathrm{mg} / \mathrm{kg} \mathrm{L}$-dopa methyl ester hydrochloride with $12 \mathrm{mg} / \mathrm{kg}$ benserazide hydrochloride, Sigma), and dyskinetic-like movements were rated using an established rodent AIMs scale (Cenci et al., 1998).

Rats $(\mathrm{n}=4)$ were injected i.p. with L-dopa/benserazide at a dose of 6 to $8 \mathrm{mg} / \mathrm{kg}$ L-dopa/12 (to 16 ) $\mathrm{mg} / \mathrm{kg}$ benserazide once daily 5 days a week for 2 weeks to obtain consistent dyskinesias, 
as previously described (Cenci et al., 1998). We used a blinded crossover design over a two week period to investigate the effects of U50,488 on dyskinetic-like movements. On Wednesday and Thursday of week one, two of the rats were injected with U50,488 (3 mg/kg, s.c., Sigma), while the other two rats were injected with vehicle (saline, s.c.) $25 \mathrm{~min}$ prior to L-dopa. During the second week, the two rats injected with U50,488 in week one were injected with saline, while the two that had been injected with saline were now injected with U50,488. The dose of U50,488 (3 mg/kg) was within the range previously used to evaluate effects on Ldopa-induced motor effects in rats (Marin et al., 2003). Solutions of L-dopa with benserazide and U50,488 were prepared immediately prior to administration.

Behavioral Assessment-An experienced blinded rater evaluated behavior using the AIMs rating scale (Cenci et al., 1998). Rats were placed in a Rotomax test chamber $(50 \mathrm{~cm}$ height $\times 34 \mathrm{~cm}$ diameter). The animals were scored from "0" (no abnormal movements) to "4" (severe, continuous abnormal movements) in four categories. These included axial dystonia, consisting of twisting posturing of the head and neck; orolingual dyskinesia, with stereotyped jaw movements and contralateral tongue protrusion; forelimb movements, with dystonic movements of the contralateral forelimb; and locomotive dyskinesia, increased locomotion with contralateral side bias. Although locomotive dyskinesia was rated, it was not included in the total because the interpretation of this motor response is not clear (Papa et al., 1994,Cenci et al., 1998). Locomotive dyskinesias are distinct from turning behavior, which was not measured in this study. Rats were observed every $20 \mathrm{~min}$ for $3 \mathrm{~h}$ following injections, and the dyskinesia rating from each session was totaled over three hours to yield a final dyskinesia score. Rats were designated as "dyskinetic" if the cumulative score was $\geq 20$ ( $n=$ 4).

\section{Non-human Primate Studies}

Nigrostriatal lesioning and drug treatments-Four female adult squirrel monkeys (Saimiri sciureus), weighing 675 - $750 \mathrm{~g}$, were purchased from Osage Research Primates (Osage Beach, MO, USA). They were individually housed with a $13 \mathrm{~h}$ light, $11 \mathrm{~h}$ dark cycle. Water was available ad libitum, and food (monkey chow pellets and fruits) provided once daily in the morning. During treatment, monkeys received fruit (no protein) in the morning (to allow for consistent absorption of L-dopa) and a full meal (monkey chow and fruit) $4 \mathrm{~h}$ after the last drug treatment. The monkeys were injected five to six times with 1.8 to $2.1 \mathrm{mg} / \mathrm{kg}$ s.c. 1 methyl-4-phenyl-1,2,3,6-tetrahydropyridine (MPTP) to induce nigrostriatal lesions, with a cumulative dose of $9.3-12.0 \mathrm{mg} / \mathrm{kg}$. The lesioned monkeys were used in previous studies to test antidyskinetic drugs. A 2-month washout was allowed between treatment regimens, during which time only L-dopa was administered to ensure consistent dyskinesias. L-dopa (5 mg/kg)/ carbidopa $(1.25 \mathrm{mg} / \mathrm{kg}$ ) was given twice daily $4 \mathrm{~h}$ apart by orogastric gavage ( 5 days on, 2 days off cycle). Monkeys were administered U50,488 (i.m. in saline) immediately prior to L-dopa. On day 1 , they received $1.0 \mathrm{mg} / \mathrm{kg}$ U50,488; on day $2,0.1 \mathrm{mg} / \mathrm{kg} \mathrm{U} 50,488$; on day $3,0.25 \mathrm{mg} /$ $\mathrm{kg}$ U50,488; on day $4,0.15 \mathrm{mg} / \mathrm{kg}$ U50,488; and on day $5,0.15 \mathrm{mg} / \mathrm{kg}$ U50,488. These doses of U50,488 $(0.1-1 \mathrm{mg} / \mathrm{kg})$ were within the range previously administered to squirrel monkeys (0.1 to $5.6 \mathrm{mg} / \mathrm{kg}$ ) (Jones and Holtzman, 1994,Pitts et al., 1998). The half-life of the drug is $8 \mathrm{~h}$ in rats (Tortella et al., 1986), therefore no washout was used between doses on the different days. Solutions of L-dopa from Sinemet ${ }^{\circledR}$ CR tablets (DuPont Pharma, Wilmington, DE, USA) and U50,488 were prepared immediately before administration. All work conformed to the National Institute of Health's Guide for the Care and Use of Laboratory Animals and was approved by the Institutional Animal Care and Use Committee.

Behavioral Assessment-Monkeys were monitored by videotape for $9 \mathrm{~h}$ daily. This includes $1 \mathrm{~h}$ of baseline taping followed by $4 \mathrm{~h}$ of taping after the first drug administration ( 9:00 h) and $4 \mathrm{~h}$ following the second drug administration ( 13:00 h). Dyskinetic movements 
(Tan et al., 2002) and parkinsonism (Hsu et al., 2004) were rated for $2 \mathrm{~min}$ at $30 \mathrm{~min}$ intervals over the $9 \mathrm{~h}$ period using established rating scales for nonhuman primates. Briefly, dyskinesias were rated as follows (Tan et al., 2002): 0 - normal behavior; 1 - subtle dyskinesias that are not sustained; 2 - mild dyskinesias that are sustained; 3 - moderate dyskinesias that impair the ability to remain stationary; and 4 - severe dyskinesias that are generalized and incapacitating. Parkinsonism was evaluated as follows: bradykinesia $(0$ - normal movement, 1 - slightly slowed movement giving it a deliberate appearance, 2 - clearly slowed movement, 3 - severely slowed movement that appeared to require great effort, and 4 - an animal that was essentially akinetic); posture $(0-3,1$ point each for parkinsonian postures of the head, trunk/legs, and arms), and tremor $(0-2,1$ point each for tremor in the legs and arms). Locomotor activity was also monitored in the home cage environment using a computerized webcam system to provide an objective measure of motor activity (Togasaki et al., 2005). Webcam activity counts were defined as the number of pixel changes per treatment period throughout the course of a day (Togasaki et al., 2005).

Statistical Analysis-All statistical analyses were preformed using GraphPad Prism (San Diego, CA, USA), with all values expressed as the mean $\pm \operatorname{SEM}(n=4)$. Significance $(P<$ 0.05 ) was determined by ANOVA followed by Bonferroni multiple comparison post hoc tests. Area under the curve, peak scores, webcam activity, and rat AIMs were analyzed by one-way ANOVA (within group factor was L-dopa \pm U50,488) and two-way ANOVA to evaluate the time course data.

\section{Results \\ Rodent studies}

Unilaterally 6-hydroxydopamine-lesioned rats chronically treated with L-dopa once daily developed AIMs, in agreement with previous work (Cenci et al., 1998). Administration of the $\kappa$-opioid receptor agonist U50,488 (3 mg/kg, s.c.) delivered $25 \mathrm{~min}$ prior to L-dopa, decreased dyskinetic-like movements by $\sim 70 \%$. The total AIM scores in saline-treated rats was $32.9 \pm$ 4.9 and in U50,488-treated rats was $12.0 \pm 4.5$. LIDs were significantly $(P<0.001)$ reduced with U50,488 treatment compared to saline administration (Fig. 1).

\section{Non-human primate studies}

Monkeys were treated with the $\kappa$-opioid receptor agonist U50,488 i.m. immediately before oral gavage of $5 \mathrm{mg} / \mathrm{kg}$ of L-dopa, a dose that yielded mild to moderate dyskinesias (Figs. 2-4). Experiments were first done to evaluate the effect of varying doses $(0.10-1.0 \mathrm{mg} / \mathrm{kg}$ i.m.) of U50,488 on peak LIDs. The results in Fig. 2A show that injection of the $\kappa$-opioid receptor agonist led to significant decreases in peak dyskinesias at the $0.15 \mathrm{mg} / \mathrm{kg}(P<0.05), 0.25(P$ $<0.001)$ and $1.0 \mathrm{mg} / \mathrm{kg}(P<0.001)$ dose. However, the U50,488-induced decline in peak dyskinesias was associated with a statistically significant $(P<0.001)$ reversal of the antiparkinsonian action of L-dopa at the $0.25 \mathrm{mg} / \mathrm{kg}$ and $1.0 \mathrm{mg} / \mathrm{kg}$, although not the $0.15 \mathrm{mg} /$ $\mathrm{kg}$ dose. Thus, parkinsonism worsened at the higher doses of the $\kappa$-opioid receptor agonist (Fig. 2B), as assessed by peak parkinsonian scores.

To determine whether U50,488 affected the overall dyskinetic response, we assessed changes in both peak and duration of dyskinetic movements by evaluating area under the curve (AUC) of the time course of LIDs (Fig. 3A). U50,488 treatment significantly $(P<0.01)$ reduced the AUC at both the 0.25 and $1.0 \mathrm{mg} / \mathrm{kg}$ doses. However, the same doses of U50,488 also significantly $(P<0.05)$ increased the parkinsonian score (AUC of the time course for parkinsonism after L-dopa administration) compared to animals not receiving the agonist (Fig. 3B). In addition, the effect of U50,488 was evaluated on the overall motor activity of the monkeys using a computerized Webcam monitoring system. There was an overall significant 
decrease in generalized motor activity in animals treated with L-dopa plus U50,488 compared to those treated with L-dopa alone $(\mathrm{F}(4,15)=3.277, P<0.04)$ (Fig. 3C).

We then further analyzed the time course of the effect of the 0.15 and $0.25 \mathrm{mg} / \mathrm{kg}$ doses of U50,488 on LIDs and parkinsonian scores. L-dopa treatment alone resulted in LIDs that reached a maximum between $60-90 \mathrm{~min}$, after which time they declined. At the $0.15 \mathrm{mg} / \mathrm{kg}$ U50,488 dose (Fig. 4A), there was a significant $(P<0.05)$ reduction in LIDs only in the afternoon at the 30 and 60 min time point after L-dopa $(\mathrm{F}(1,126)=12.15, P<0.0007)$. At the higher dose $(0.25 \mathrm{mg} / \mathrm{kg}), \mathrm{U} 50,488$ treatment completely abolished LIDs at all time points (F $(1,126)=191.14, P<0.0001)$ (Fig. 4B). However, administration of U50,488 also reversed the antiparkinsonian effect of L-dopa at both the $0.15 \mathrm{mg} / \mathrm{kg}$ dose $(\mathrm{F}(1,126)=11.04, P<$ $0.0012)$ and the $0.25 \mathrm{mg} / \mathrm{kg}$ dose $(\mathrm{F}(1,126)=96.66, P<0.0001)$ compared to animals not receiving the agonist (Fig 4C,D).

Side effects that developed with U50,488 treatment included vomiting and sedation (Table 1). There were no side effects with the lowest dose of U50,488 $(0.10 \mathrm{mg} / \mathrm{kg})$; however, this dose did not reduce LIDs. In contrast, results from individual animals show that there were variable effects of U50,488 on dyskinesias, vomiting and sedation at the $0.15 \mathrm{mg} / \mathrm{kg}$ dose. For instance, we observed a decrease in dyskinesias with no side effects, a decrease in dyskinesias with only sedation but no vomiting, and a decrease in dyskinesias with only vomiting but no sedation. With the $0.25 \mathrm{mg} / \mathrm{kg}$ dose, on the other hand, there is sedation and a decrease in dyskinesias despite vomiting. At the highest dose of U50,488 $(1.0 \mathrm{mg} / \mathrm{kg})$ that prominently reduced LIDs, side effects were very notable, and included vomiting and sedation.

\section{Discussion}

Extensive studies in both rodent and nonhuman primate models, as well as studies in humans, suggest a role for the striatal opioid system in the development of LIDs (Morissette et al., 1997,Cenci et al., 1998,Duty et al., 1998,Henry et al., 1999,Johansson et al., 2001, Quik et al., 2002,Tel et al., 2002,Winkler et al., 2002,Henry et al., 2003,Carta et al., 2005,Aubert et al., 2006). Evidence for this possibility stems from results showing that enhanced PPE-B transcript levels correlate well with LIDs in experimental parkinsonian models and Parkinson's disease (Duty et al., 1998,Henry et al., 1999, Tel et al., 2002,Henry et al., 2003,Aubert et al., 2006).

As well, there are changes in opioid receptor subtype expression in various regions of the basal ganglia after chronic L-dopa treatment (Johansson et al., 2001,Aubert et al., 2006).

Interestingly, the most distinct difference between L-dopa-treated dyskinetic and nondyskinetic rats is a decrease in $\kappa$-opioid receptors in the striatum and the nigra, that is inversely correlated with dyskinetic scores (Johansson et al., 2001). More recent work in nonhuman primates also shows significant declines in $\kappa$-opioid, as well as $\mu$-opioid receptors in the globus pallidus and/or striatum with LIDs (Aubert et al., 2006). These declines in basal ganglia $\kappa$-opioid receptor levels in rats and monkeys may represent a compensatory feedback mechanism in response to enhanced PPE transcript levels (Duty et al., 1998,Henry et al., 1999, Tel et al., 2002,Henry et al., 2003,Aubert et al., 2006). This hypothesis assumes that the elevated mRNA levels are associated with an increase in endogenous opioids that stimulate the various opioid receptor subtypes to activate intracellular signaling pathways responsible for the development of LIDS. The opioid-induced decrease in $\mu$ - and $\kappa$-opioid receptor levels (Johansson et al., 2001,Aubert et al., 2006) may lead to declines in functions that normally attenuate LIDS. Such an interpretation would suggest that treatments that activate $\kappa$ - or $\mu$ opioid receptors may reduce LIDs. Although somewhat paradoxical, this would be similar to observations that long term agonist treatment downregulates neurotransmitter receptors and yet is effective therapeutically, for example, dopamine agonists for the treatment of Parkinson's disease. On the other hand, the in vivo situation with the opioid system may be more complex 
because of differential alterations in various opioid peptides that may interact with multiple opioid receptor subtypes $(\delta, \kappa$ and $\mu)$. This complexity is evident from previous studies showing that both opioid agonists and antagonists reduce dyskinesias depending on the specific experimental conditions. Further studies are required to elucidate the mechanisms through which opioid compounds modulate the occurrence of LIDs.

Limited studies done in rats have shown that that $\kappa$-opioid receptor-stimulation may be involved in L-dopa-induced motor fluctuations (Marin et al., 1996, Marin et al., 2003). Administration of the $\kappa$-opioid receptor agonist U50,488 immediately before L-dopa to unilateral 6-hydroxydopamine lesioned rats partially reversed L-dopa-induced contralateral rotations (Marin et al., 2003). Because changes in L-dopa-induced contralateral rotations in rats may reflect effects both on parkinsonian and dyskinetic-like movements, we evaluated behavioral components more closely linked to LIDs. This included axial dystonia, orolingual dyskinesia, and dystonic movements of the contralateral forelimb as previously described (Cenci et al., 1998). In agreement with the work of Marin and colleagues (Marin et al., 2003), our results in rodents show that activation of $\kappa$-opioid receptors using U50,488 reduced Ldopa-induced AIMs. These present studies combined with previous work in a rodent model (Marin et al., 1996,Marin et al., 2003), suggest that א-opioid receptors are important in the pathophysiology of L-dopa-induced motor abnormalities and that agonists may represent a useful therapeutic intervention for LIDs. We therefore initiated a series of experiments in nonhuman primates, as this model offers the advantage that the effects of drugs on parkinsonism and LIDs can be clearly and easily identified, and are highly reminiscent of the clinical features seen in humans with the disease. Our data showed that there was a dramatic decline in LIDs with U50,488, particularly at the higher doses. This included both a decrease in peak dose dyskinesias and duration of the dyskinetic response. However, this attenuated dyskinetic response was paralleled by a dose-related increase in parkinsonism with U50,488 treatment as compared to animals not receiving the drug. Only at the $0.15 \mathrm{mg} / \mathrm{kg}$ dose of U50,488 was there a small significant decline in peak dyskinesias scores with no significant change in the parkinsonian score. However, the small therapeutic window suggests this would not be of practical clinical value. These findings raise questions about the usefulness of $\kappa$ opioid receptor agonists for the treatment of LIDs. Furthermore, the presence of side effects, such as severe vomiting and sedation (Dykstra et al., 1987), would contraindicate the therapeutic use of $\kappa$-opioid receptor agonists or at least U50,488. There appeared to be no clearcut relationship between the occurrence of dyskinesias and sedation at the intermediate doses of U50,488, since declines in dyskinesias occurred with or without of sedation. Similarly, there was a variable association between vomiting and sedation, and the reduction in dyskinesias. These findings may suggest the mechanisms through which $\kappa$-opioid agonists decrease LIDs are not similar to those that induce vomiting and sedation. Conceivably, different opioid systems throughout the CNS mediate these different biological responses.

The use of nonselective, as well as subtype specific opioid receptor drugs as a therapeutic intervention for LIDs is currently under investigation. The nonselective opioid receptor agonist morphine reduces dyskinetic movements in patients with Parkinson's disease and also in primates with LIDs (Berg et al., 1999,Samadi et al., 2004). Nonselective opioid receptor antagonists, such as naloxone and naltrexone, have also been tested with variable effects in monkeys and humans including no change, increases or decreases in LIDs (Rascol et al., 1994,Klintenberg et al., 2002,Samadi et al., 2003,Fox et al., 2004,Samadi et al., 2004). These conflicting results with the nonselective opioid antagonists may be due to activation of varying subtypes in the different studies. This may lead to multiple, possibly opposing actions in the striatum, with a complex repertoire of behavioral outcomes. These findings suggest that the use of drugs targeted to select subtypes may yield more consistent results and, in fact, one study showed that antagonists directed to $\mu$ - and/or $\delta$-opioid receptor diminished LIDs in L-dopatreated marmosets (Henry et al., 2001). However, the observation that the nonselective agonist 
morphine reduces LIDs (Berg et al., 1999, Samadi et al., 2004) suggests that regulation of LIDs by the opioid system may be complex and involve activation of more than one receptor subtype.

In summary, the present results show that $\kappa$-opioid receptor agonists, such as U50,488 reduce LIDs in a nonhuman primate model, supporting the hypothesis that activation of these receptors plays a role in the development of dyskinesias. However, the antiparkinsonian effect of U50,488 suggest that this class of drugs is not suitable for reducing LIDs in humans with Parkinson's disease. The significant side effects raise further questions regarding its usefulness in a clinical setting.

\section{Acknowledgements}

This work was supported by National Institute of Health Grant NIH NS34886

\section{References}

Aubert I, Guigoni C, Li Q, Dovero S, Bioulac BH, Gross CE, Crossman AR, Bloch B, Bezard E. Enhanced Preproenkephalin-B-Derived Opioid Transmission in Striatum and Subthalamic Nucleus Converges Upon Globus Pallidus Internalis in L-3,4-dihydroxyphenylalanine-Induced Dyskinesia. Biol Psychiatry. 2006

Berg D, Becker G, Reiners K. Reduction of dyskinesia and induction of akinesia induced by morphine in two parkinsonian patients with severe sciatica. J Neural Transm 1999;106:725-728. [PubMed: 10907730]

Bezard E, Brotchie JM, Gross CE. Pathophysiology of levodopa-induced dyskinesia: potential for new therapies. Nat Rev Neurosci 2001;2:577-588. [PubMed: 11484001]

Carta AR, Tronci E, Pinna A, Morelli M. Different responsiveness of striatonigral and striatopallidal neurons to L-DOPA after a subchronic intermittent L-DOPA treatment. Eur J Neurosci 2005;21:11961204. [PubMed: 15813929]

Cenci MA, Lee CS, Bjorklund A. L-DOPA-induced dyskinesia in the rat is associated with striatal overexpression of prodynorphin- and glutamic acid decarboxylase mRNA. Eur J Neurosci 1998;10:2694-2706. [PubMed: 9767399]

Duty S, Henry B, Crossman AR, Brotchie JM. Topographical organization of opioid peptide precursor gene expression following repeated apomorphine treatment in the 6-hydroxydopamine-lesioned rat. Exp Neurol 1998;150:223-234. [PubMed: 9527891]

Dykstra LA, Gmerek DE, Winger G, Woods JH. Kappa opioids in rhesus monkeys. I. Diuresis, sedation, analgesia and discriminative stimulus effects. J Pharmacol Exp Ther 1987;242:413-420. [PubMed: 3612543]

Fox S, Silverdale M, Kellett M, Davies R, Steiger M, Fletcher N, Crossman A, Brotchie J. Non-subtypeselective opioid receptor antagonism in treatment of levodopa-induced motor complications in Parkinson's disease. Mov Disord 2004;19:554-560. [PubMed: 15133820]

Gouarderes C, Tellez S, Tafani JA, Zajac JM. Quantitative autoradiographic mapping of delta-opioid receptors in the rat central nervous system using [125I][D.Ala2]deltorphin-I. Synapse 1993;13:231240. [PubMed: 8388577]

Henry B, Crossman AR, Brotchie JM. Effect of repeated L-DOPA, bromocriptine, or lisuride administration on preproenkephalin-A and preproenkephalin-B mRNA levels in the striatum of the 6-hydroxydopamine-lesioned rat. Exp Neurol 1999;155:204-220. [PubMed: 10072296]

Henry B, Duty S, Fox SH, Crossman AR, Brotchie JM. Increased striatal pre-proenkephalin B expression is associated with dyskinesia in Parkinson's disease. Exp Neurol 2003;183:458-468. [PubMed: 14552886]

Henry B, Fox SH, Crossman AR, Brotchie JM. Mu- and delta-opioid receptor antagonists reduce levodopa-induced dyskinesia in the MPTP-lesioned primate model of Parkinson's disease. Exp Neurol 2001;171:139-146. [PubMed: 11520128]

Hsu A, Togasaki DM, Bezard E, Sokoloff P, Langston JW, Di Monte DA, Quik M. Effect of the D3 dopamine receptor partial agonist BP897 [N-[4-(4-(2-methoxyphenyl)piperazinyl)butyl]-2- 
naphthamide] on L-3,4-dihydroxyphenylalanine-induced dyskinesias and parkinsonism in squirrel monkeys. J Pharmacol Exp Ther 2004;311:770-777. [PubMed: 15226382]

Johansson PA, Andersson M, Andersson KE, Cenci MA. Alterations in cortical and basal ganglia levels of opioid receptor binding in a rat model of 1-DOPA-induced dyskinesia. Neurobiol Dis 2001;8:220239. [PubMed: 11300719]

Jones DN, Holtzman SG. Behavioral effects of systemically administered mu and kappa opioid agonists in the squirrel monkey: peptides versus alkaloids. Pharmacol Biochem Behav 1994;47:421-426. [PubMed: 7911572]

Kaneko T, Minami M, Satoh M, Mizuno N. Immunocytochemical localization of mu-opioid receptor in the rat caudate-putamen. Neurosci Lett 1995;184:149-152. [PubMed: 7715834]

Klintenberg R, Svenningsson P, Gunne L, Andren PE. Naloxone reduces levodopa-induced dyskinesias and apomorphine-induced rotations in primate models of parkinsonism. J Neural Transm 2002;109:1295-1307. [PubMed: 12373562]

Linazasoro G. New ideas on the origin of L-dopa-induced dyskinesias: age, genes and neural plasticity. Trends Pharmacol Sci 2005;26:391-397. [PubMed: 16009432]

Marin C, Bove J, Bonastre M, Tolosa E. Effect of acute and chronic administration of U50,488, a kappa opioid receptor agonist, in 6-OHDA-lesioned rats chronically treated with levodopa. Exp Neurol 2003;183:66-73. [PubMed: 12957489]

Marin C, Engber TM, Chaudhuri P, Peppe A, Chase TN. Effects of kappa receptor agonists on D1 and D2 dopamine agonist and antagonist-induced behaviors. Psychopharmacology (Berl) 1996;123:215221. [PubMed: 8741947]

Meng F, Xie GX, Thompson RC, Mansour A, Goldstein A, Watson SJ, Akil H. Cloning and pharmacological characterization of a rat kappa opioid receptor. Proc Natl Acad Sci U S A 1993;90:9954-9958. [PubMed: 8234341]

Morissette M, Goulet M, Soghomonian JJ, Blanchet PJ, Calon F, Bedard PJ, Di Paolo T. Preproenkephalin mRNA expression in the caudate-putamen of MPTP monkeys after chronic treatment with the D2 agonist U91356A in continuous or intermittent mode of administration: comparison with L-DOPA therapy. Brain Res Mol Brain Res 1997;49:55-62. [PubMed: 9387863]

Papa SM, Engber TM, Kask AM, Chase TN. Motor fluctuations in levodopa treated parkinsonian rats: relation to lesion extent and treatment duration. Brain Res 1994;662:69-74. [PubMed: 7859092]

Paxinos, G.; Watson, C. The rat brain in stereotaxic coordinates. 2. Academic Press; UK: 1986.

Pitts RC, Allen RM, Walker EA, Dykstra LA. Clocinnamox antagonism of the antinociceptive effects of mu opioids in squirrel monkeys. J Pharmacol Exp Ther 1998;285:1197-1206. [PubMed: 9618423]

Quik M, Police S, Langston JW, Di Monte DA. Increases in striatal preproenkephalin gene expression are associated with nigrostriatal damage but not L-DOPA-induced dyskinesias in the squirrel monkey. Neuroscience 2002;113:213-220. [PubMed: 12123699]

Rascol O, Fabre N, Blin O, Poulik J, Sabatini U, Senard JM, Ane M, Montastruc JL, Rascol A. Naltrexone, an opiate antagonist, fails to modify motor symptoms in patients with Parkinson's disease. Mov Disord 1994;9:437-440. [PubMed: 7969211]

Samadi P, Gregoire L, Bedard PJ. Opioid antagonists increase the dyskinetic response to dopaminergic agents in parkinsonian monkeys: interaction between dopamine and opioid systems. Neuropharmacology 2003;45:954-963. [PubMed: 14573388]

Samadi P, Gregoire L, Bedard PJ. The opioid agonist morphine decreases the dyskinetic response to dopaminergic agents in parkinsonian monkeys. Neurobiol Dis 2004;16:246-253. [PubMed: 15207281]

Satoh M, Minami M. Molecular pharmacology of the opioid receptors. Pharmacol Ther 1995;68:343364. [PubMed: 8788562]

Tan LC, Protell PH, Langston JW, Togasaki DM. The hyperkinetic abnormal movements scale: a tool for measuring levodopa-induced abnormal movements in squirrel monkeys. Mov Disord 2002;17:902-909. [PubMed: 12360538]

Tel BC, Zeng BY, Cannizzaro C, Pearce RK, Rose S, Jenner P. Alterations in striatal neuropeptide mRNA produced by repeated administration of L-DOPA, ropinirole or bromocriptine correlate with dyskinesia induction in MPTP-treated common marmosets. Neuroscience 2002;115:1047-1058. [PubMed: 12453478] 
Togasaki DM, Hsu A, Samant M, Farzan B, DeLanney LE, Langston JW, Di Monte DA, Quik M. The Webcam system: a simple, automated, computer-based video system for quantitative measurement of movement in nonhuman primates. J Neurosci Methods 2005;145:159-166. [PubMed: 15922034]

Tortella FC, Robles L, Holaday JW. U50,488, a highly selective kappa opioid: anticonvulsant profile in rats. J Pharmacol Exp Ther 1986;237:49-53. [PubMed: 3007743]

Winkler C, Kirik D, Bjorklund A, Cenci MA. L-DOPA-induced dyskinesia in the intrastriatal 6hydroxydopamine model of parkinson's disease: relation to motor and cellular parameters of nigrostriatal function. Neurobiol Dis 2002;10:165-186. [PubMed: 12127155] 


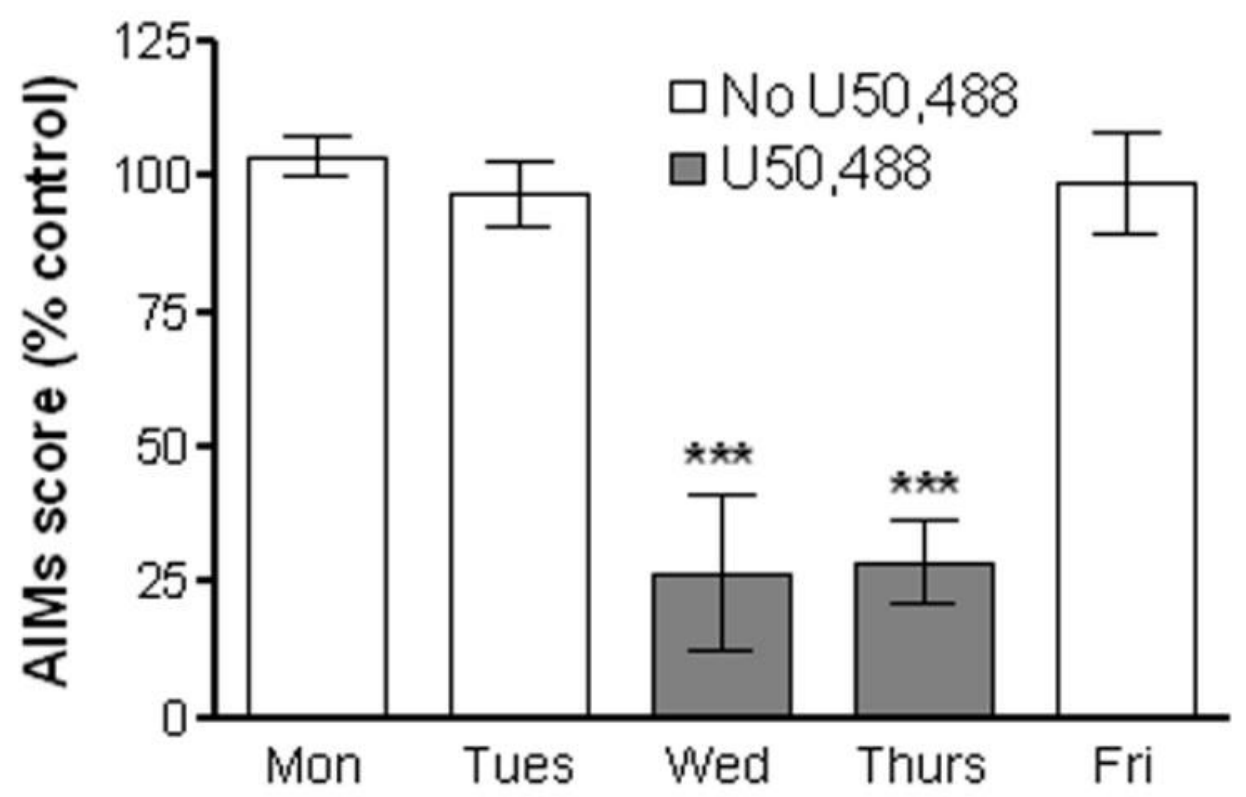

Fig 1.

The effect of the $\kappa$-opioid receptor agonist, U50,488, on daily cumulative AIM scores after Ldopa treatment in 6-OHDA lesioned rats. The rats were injected s.c with saline on Monday (Mon), Tuesday (Tues) and Friday (Fri). They were then injected with U50,488 (3 mg/kg) or saline on Wednesday (Wed) and Thursday (Thurs), using a crossover design as described in the Methods. This was followed 25 min later by i.p. administration of L-dopa. Dyskinetic-like movements were quantified with the AIM scale by a blinded rater. Each bar represents the mean \pm SEM of 4 rats. $* * * P<0.001$ compared to days with no U50,488 treatment. 

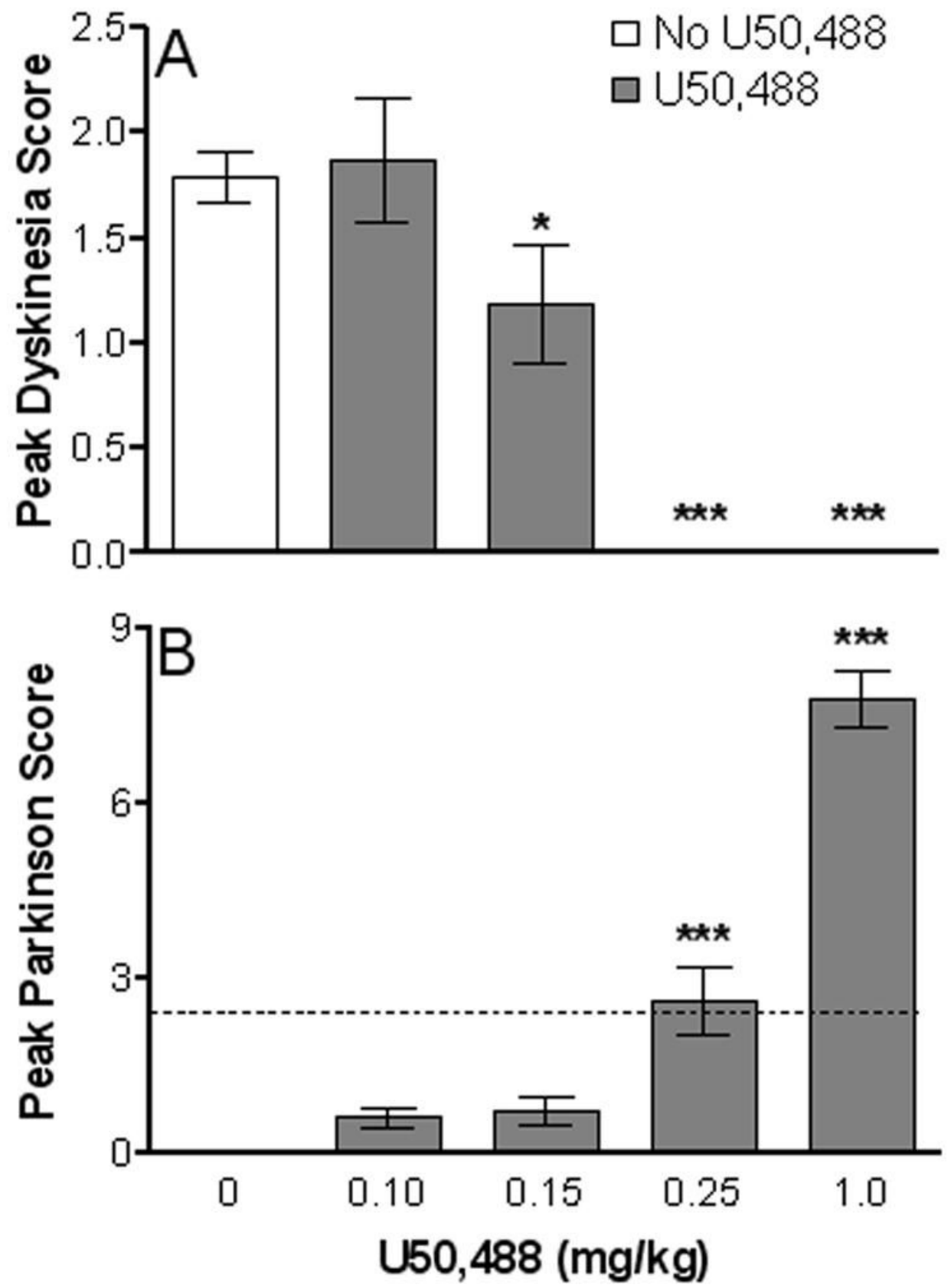

Fig 2.

Peak dyskinetic and anti-parkinsonian responses to L-dopa (5 mg/kg, p.o.) and U50,488 (0.1 $-1.0 \mathrm{mg} / \mathrm{kg}$, i.m.). Behavioral assessments were performed at $2 \mathrm{~min}$ intervals every $30 \mathrm{~min}$ from videotapes. Values represent the average maximum dyskinesia (A) and minimum parkinsonian (B) scores from morning and afternoon treatment periods. (B) The dashed line represents baseline Parkinson ratings averaged over a $1 \mathrm{~h}$ period prior to drug administration. Each bar represents the mean \pm SEM of 4 monkeys. $* P<0.05$ and $* * * P<0.001$ compared to no U50,488 treatment. 

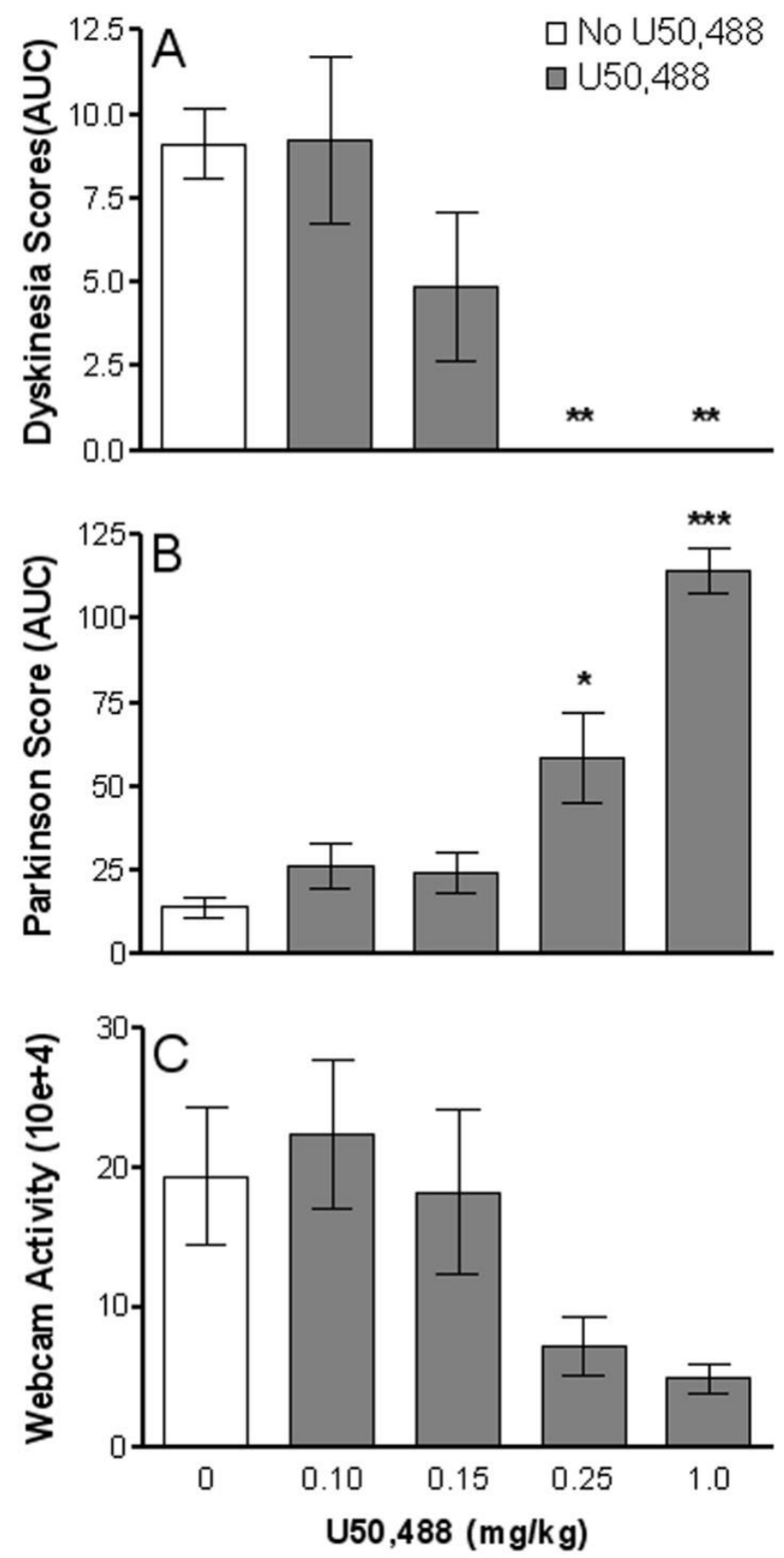

Fig 3.

Overall effect of U50,488 on LIDs, parkinsonism and motor activity. Behavioral assessments were done at $2 \mathrm{~min}$ intervals every $30 \mathrm{~min}$ from videotapes. All values represent average total ratings for each dose of U50,488. Area under the curve (AUC) includes peak and duration of dyskinesias (A) and parkinsonism (B) for each monkey. (C) Depicts webcam measurements of motor activity during the course of L-dopa treatment with and without U50,488. Each bar represents the mean \pm SEM of 4 monkeys. $* P<0.05$, $* * P<0.01$, and $* * * P<0.001$ compared with no U50,488 treatment. 

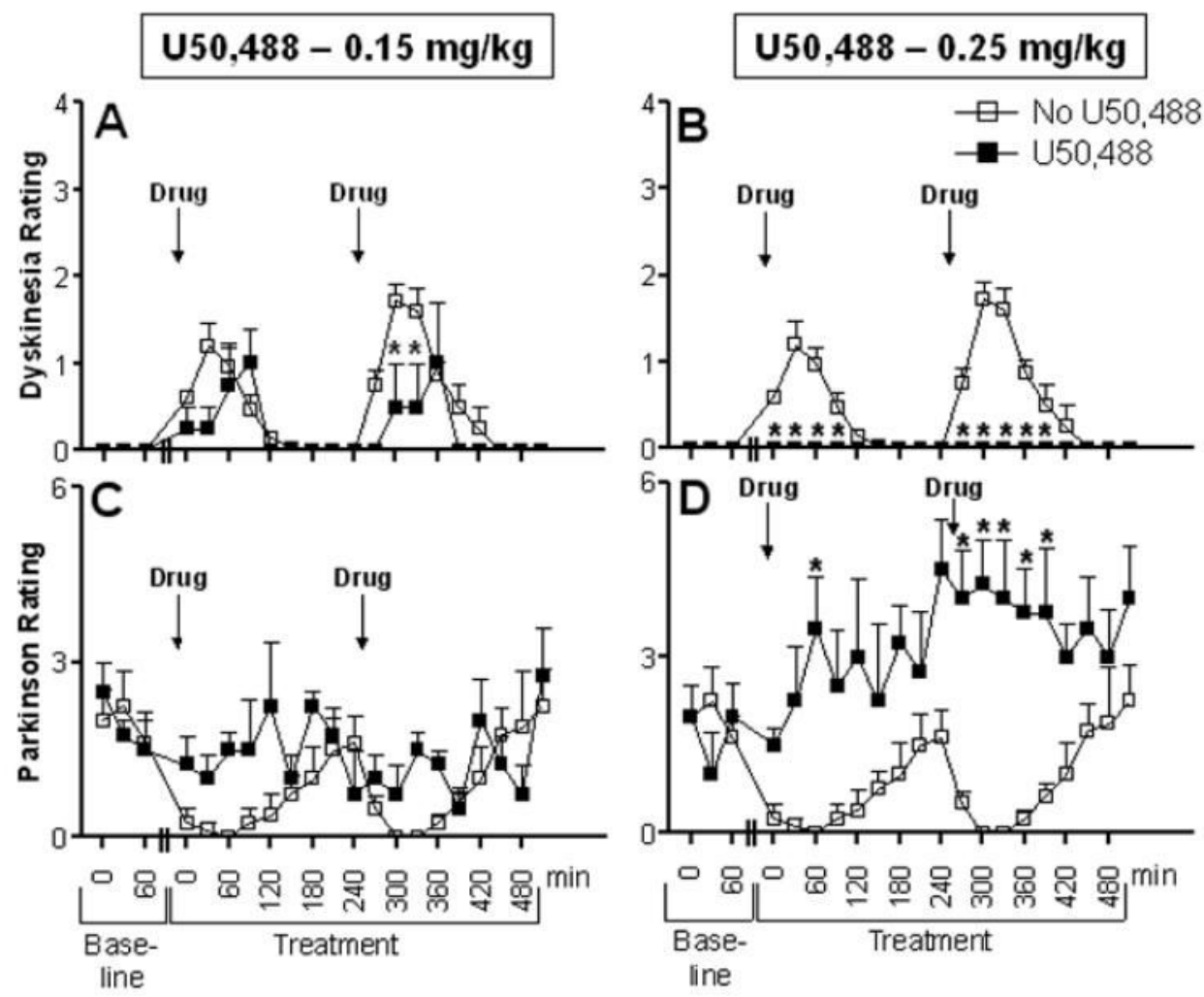

Fig 4.

Time course of dyskinesia and parkinsonian ratings in MPTP-lesioned monkeys. Baseline behavior was obtained for $1 \mathrm{~h}$. U50,488 (0.15 and $0.25 \mathrm{mg} / \mathrm{kg}$, i.m. $)$ was then administered immediately followed by L-dopa (5 mg/kg, p.o.). Drugs were given at 9:00 and 13:00 h. Behavioral assessments were done at $2 \mathrm{~min}$ intervals every $30 \mathrm{~min}$ for the full $9 \mathrm{~h}$ from videotapes. Each symbol represents the mean \pm SEM of 4 monkeys. ${ }^{*} P<0.05$, compared to no U50,488 treatment. 


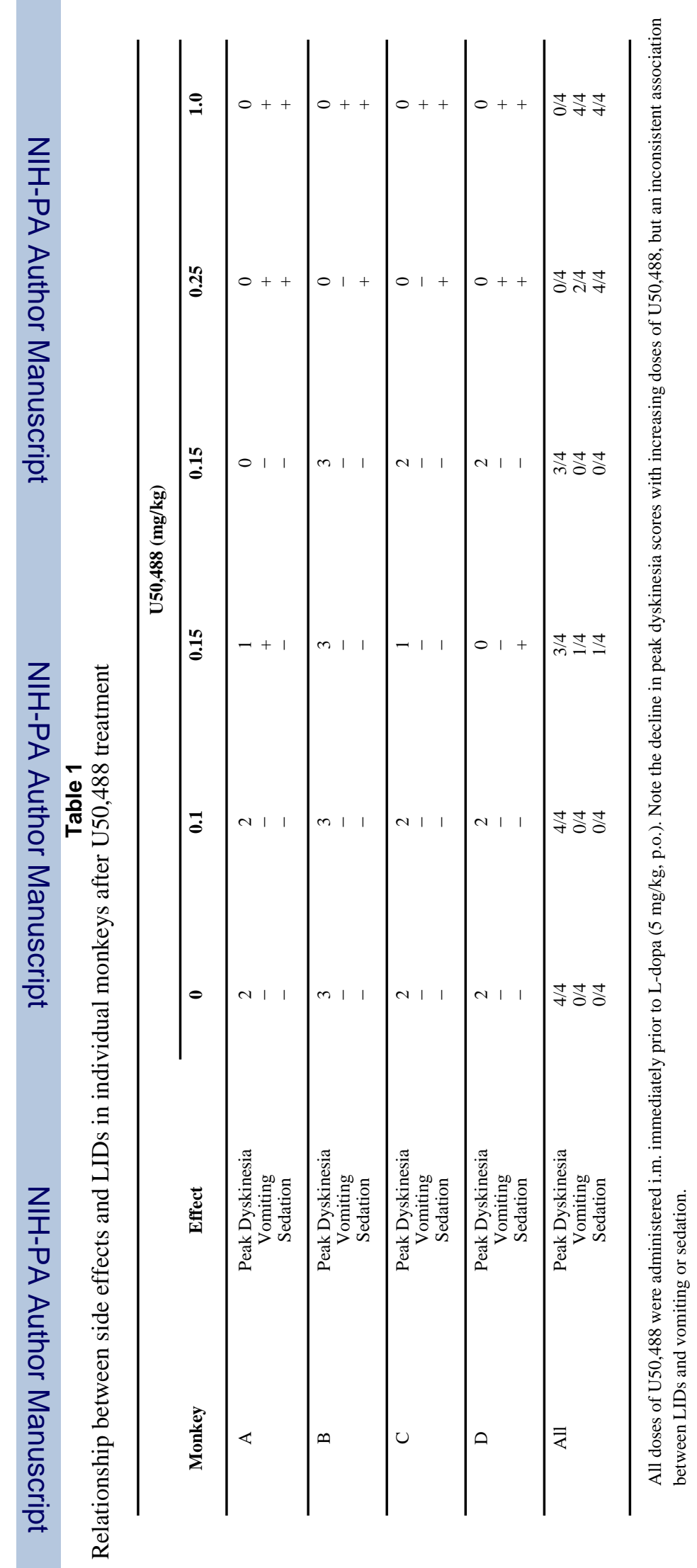

Exp Neurol. Author manuscript; available in PMC 2008 May 1. 